\title{
EL MEXICANISMO Y NUESTRA LITERATURA *
}

\author{
POR
}

\section{JOSE ROJAS GARCIDUEÑA}

GE INICia nuestra literatura bajo el signo del Renacimiento, que lleva en Su propia esencia ana proyección de universalidad, ajena a toda limitación nacionalista, ya que su ideal está remoto en el espacio y en el tiempo, fijo en unos cuăntos puntos del Mediterráneo y en unos cuantos momentos de la historî greco-romana.

Porque es indudable el renacentismo de Francisco de Terrazas, nuestro primer lírico, cuyos sonetos siguen tan de cerca a los del Divino Herrera y todavía recuerdan los de aquel gran renacentista, soldado, cortesano y poeta Garcilaso de la Vega. Aunque en otro tono, renacentista es también Córdoba y Bocanegra, muy dentro del Renacimiento español, es decir con las limitaciones y tanteos propios de una época de transición; otro tanto sucede al teatro prelopista en cuyo marco deben inscribirse los Coloquios de González de Eslava. Semejante en el hálito que la inspira,

* Conferencia sustentada en el Aula Martí, durante los Cursos de Inviemo, en la Facultad de Filosofia y Letras, el 29 de febrero de 1952. 
es la épica, hoy tan perdida, que va del ya citado Terrazas a los poemas de Arias de Villalobos, destacando enmedio la figura más ilustre de nuestra poesía renacentista: Bernardo de Balbuena, lector asiduo de latinos y seguidor próximo de Juan de la Cueva y otros poetas renacjentes.

En todo tiempo, que comprende más de casi tres cuartos de siglo a partir de la Conquista de México, la literatura de Nueva España sigue de cerca los pasos de la española y de casi toda la europea sin más trazas de preocupación por lo que pudiera ser diferencial, propio y local, que los vocablos relativos a "cosas de la tierra", lo cual puede dar de vez en cuando alguna nota pintoresca, pero de ninguna manera expresan intención profunda ni preocupación sincera.

Viene luego el barroco, lento y contenido al principio, violento $y$ extremoso al final, que recorre su largo ciclo retorciéndose como sus propias columnas salomónicas, dando un carácter hasta entonces inusitado a las formas pero sin apartarse nunca esencialmente de los ejes clásicos que le daban estructura y elementos, motivos y alegorías, ideales y paradigmas y que, por lo mismo, no pierde nunca su raíz clásica y universal. Ciertamente hay notas mexicanas $y$ hasta mexicanistas, unas pocas en Sigüenza y algunas más en Sor Juana, por no mencionar sino a las dos cúspides del siglo Xvil; mas predomina de modo incuestionable el torrente de los poetas y de los poemas del Triunfo Parténico y de los otros concurridos y frecuentes certámenes; en cantidad $y$, sobre todo, en calidad, incluyendo las obras antes aludidas de Sigüenza y de Sor Juana, los acentos del barroco siguen siendo los ecos del clasicismo, de ningún modo opacados ni disminuídos por las leves pinceladas de colorido local que pueden fácilmente encontrarse.

$Y$ si tal cosa es verdad en ese barroco cada vez más mexicano pero casi nunca mexicanista, los rasgos locales casi se borran del todo cuando, ya entrada la segunda mitad del siglo xviri, triunfa el neoclacisismo purista, frío y academizante, anhelando vincularse directantente con los modelos remotos, sin importarle abandonar, y a veces destruyendo deliberadamente los aspectos particulares, próximos y típicos de los varios países y de las diversas naciones que empezaban a forjarse.

La Independencia, por su propia indole política y por el desgarramiento que planteaba, significó un largo momento excepcionalmente favorable al desarrollo del sentimiento de nacionalidad $y$, por lo tanto, al cultivo de cualquier género artístico que sirviese de expresión a la pasión patriótica. Así claramente se ve en Fernández de Lizardi, y muchas veces 
eso se ha tomado como signo y símbolo de toda una época; pero tal juicio peca de excesivo pues el gesto del Pensador Mexicano, aunque sin duda el más trascendente, visto en el marco de su tiempo, se mira aun hoy envuelto entre las ondas de un neoclacisismo ya en decadencia.

Cierto que aquella semilla costumbrista y crítica, fácil productora de florecimiento mexicanista, creció durante el Romanticismo en cuya segunda fase produce obras que son espejos de mexicanismo, como gran parte de los escritos de Guillermo Prieto, los de Tomás de Cuéllar y otros que se les asemejan.

El impulso venía de tiempo atrás: Prieto encontraba que los mejores timbres de la Academia de Letrán estaban en su "tendencia decidida a mexicanizar la literatura, emancipándola de toda otra..." Después del paréntesis de las guerras (de Reforma, la Intervención y el Imperio), el impulso revive más claro y fuerte y en ello tuvo gran parte Altamirano, con su largo esfuerzo de veinte años, que realizó en revistas y conferencias, en la cátedra y en el Liceo Hidalgo, hasta formar una poderosa corriente de nacionalismo literario. El movimiento fue de gran importancia y la orientación decisiva; los frutos salieron, como siempre, variados y diversos, pues si nadie debe negar lo mucho que a todo eso deben las letras mexicanas, tampoco podrian dejarse de censurar excesos como aquellas palabras de Francisco Sosa, allá por 1874 que, refiriéndose a Sor Juana le reconocía talento e inteligencia "pero que según un 'criterio $\mathrm{Na}$ cional' no encontraba en los escritos de la poetisa modelos dignos de ser imitados y menos de'colocarla entre los escritores mexicanos...", 1 opinión corriente entre los guías de la época: Altamirano, Pimentel, etc. y que Sosa no hacia mas que resumir.

Probablemente quien ante todo eso ha sonreido con más finura es Genaro Estrada que en uno de los capitulos iniciales de su Pero Galín, trae estos párrafos que voy a citar porque, a más de ser oportunos, suavizarán la exposición de este resumen, con su toque de ironía:

"Hubo, hace todavía pocos años, un revuelo de agudo regionalismo en la literatura americana. Entonces, como ahora, usóse la palabra tendencia para justificar el revuelo. Trátase, decian los enterados, "de un vigoroso movimiento hacia el arte autóctono". Cada vez que se habla del

1 Alicta Pronles Ojeda.-las Asociaciones Literarias de México, Siglo $X I X$. Tesis para optar grado en la Facultad de Filosofia y Letras.-Ed. mimeográfica,-México, 1951, pág. 78. 
arte autóctono, ya se sabe que es un atrevimiento discutir la tendencia autóctona de ese arte.

"Eran los tiempos en que los poetas líricos se acogieron a la poesía épica; tiempos de Tabaré y de Chimborazo, de Tequendama $y$ de Popocatépetl, de selva virgen y de Amazonas, de águilas altivas y de "cóndor colosal de orlado cuello". Fresco estaba aún el recuerdo de aquel "espléndido es tu cielo, patria mía, de un purísimo azul como el zafiro..."

"Y al grito de "hay que ir a lo nuestro" los poetas preludiaban sus odas, invariablemente, pidiendo la lira, ya a Apolo, ya a Zeus, ya a Clío, ya al historiador de más popular consagración de su república. ; Dadme la Jira! ; traed la lira! ; quiero la lira de robusto acento! $Y$, después, las subdivisiones : la septicorde, la tricorde y "la más pesada y negra".

"Todo lo que fuera americanismo teníase por "el último grito". Y si lo continental presentábase como nacional y lo nacional se sazonaba con sabores de la región y de la provincia, el éxito estaba más asegurado. Así "El último grito" tornóse en una ensordecedora gritería continental cuyos postreros ecos - ya más afinados y seguros- diólos la poesia de Chocano.

"Lo indígena, particularmente; fue lo preferido. $Y$ era explicable, porque llegaba más a lo hondo de lo autóctono...

"En México el arqueólogo don Cecilio A. Robelo, dado también a devaneos de semántica, desentrañaba la teogonía nahoa de los cuatro soles, en aquel canto cuya lectura era inútil de intentar si no se tenía a la mano el Diccionario de Aztequismos del propio autor:

El Gran Ometecuhtli en Omeyocan, con Omecihuatl, su inmortal consorte...

"Aquella fue, en la literatura española de América, la hora del Gran Ometecuhtli". 2

Exhausto el Romanticismo lo substituye un realismo en la prosa favorable a los cultivos localistas; mas en poesía la trayectoria es diferente porque el Modernismo no es localista ni pintoresco ni folklorista y, por lo tanto no podía ser mexicanista: cultiva temas propios con una inclinación marcada hacia las fugas en el espacio y en el tiempo que producen remembranzas y exotismos de los que darian fáciles ejemplos las obras de.Tablada, de Rebolledo y aún del propio Amado Nervo. Y, hasta los poetas que labran su campo fuera de las áreas del modernismo, así Díaz Mirón y Manuel José Othón, tampoco podrían llamarse mexica-

2. Gekaro Estrada-Pero Galim.-Ed. Cultura; México, 1926. 
nistas, ni menos aún los próceres del Humanismo que nunca han dejado de beber en las viejas fuentes y han mantenido el latinismo en las páginas de Montes de Oca, de Pagaza y de tantos otros hasta nuestros días.

Vuelve a resurgir la tendencia popular nacionalista, mexicanista, en el polvo y el humo de la Revolución; desnuda y objetiva en Los de Abajo, y luego, tras la agitación de los días álgidos, depurada, fina y metafórica con López Velarde.

Asi pues, las tendencias universalistas y mexicanistas forman, en conjunto, un movimiento ondulante, de amplio ritmo, predominando to que de uno o varios modos resulta universal (pero no exótico ni ajeno), sobre las corrientes menos durables y más débiles, a pesar del engañoso auge que tienen, en parte de nuestro siglo, las modalidades de tónica mexicanista.

Henriquez Ureña, en conferencias y ensayos memorables, atisbó trazos iniciales de lo mexicano en Ruiz de Alarcón, que es del todo insospechable de huellas mexicanistas. Mexicana es la literatura, probablemente toda, de Sor Juana y rasgos mexicanistas, apenas estimables como jugueteos y chistes, sus versos en el balbuceo defectuoso de los indios o en las breves pinceladas en que adrede convierte elementos de toponimia $u$ otros análogos en toques coloristas equivalentes a esas flores, plantas o rasgos indigenas que a veces surgen entre el follaie de los acantos, en los capiteles, frisos o cornisas, en el florecimiento de los elementos clásicos del barroco. Por todo nuestro arte pasa igual cosa: es evidente y nos encanta la influencia indigena en barroco de Tonantzintla, pero este barroco, justamente llamado bárbaro, no puede caracterizar nuestra arquitectura del sigio Xvi mejor representada por ese barroco "culto" de Tepotzotlán o del Rosario de Puebla.

De igual modo es más mexicanista, pero no más mexicano, Guillermo Prieto con sus "chinas" de castor y jarabe que el austero y violento Nigromante con sus odas y tercetos llenos de remembranzas clásicas. No hay localismo mexicanista en el Idilio Salvaje de Othón, pues el desierto que canta ni siquiera es exclusivamente mexicano, ya que igual aspecto presenta en ambos lados de la frontera, pero el enfoque sensible, el acento interno, la tonalidad general del poema trasciende a cosa nuestra de modo indudable.

No es mexicanista ni lo mayor ni lo mejor de nuestras letras; hay, como dije, un movimiento ondulante, nunca un desarrollo rectilineo y ni siquiera una curva parabólica. No es, pues, tradición predominante, pero 
tampoco ha sido la ausencia de mexicanismos obstáculo ninguno ni tropiezo mínimo en el desarrollo continuo y creciente, aunque no fácilmente perceptible, de la nacionalidad de nuestras letras.

Con ello toco la linde de un campo por el que deliberadamente no deseo mucho adentrarme. El desarrollo, el robustecimiento de las correspondencias que existan entre el complejo psico-social que es la nacionalidad y su versión en las artes y en las letras, eso es cosa de otro tema que no me corresponde ni quiero tratar. Pero, sin necesidad de acotaciones difíciles ni de honduras poco exploradas, es evidente y fácilmente perceptible la diferencia entre una literatura mexicana y una literatura mexicanista, entre una expresión de lo nacional y las expresiones nacionalistas.

La nación es un complejo social-jurídico-cultural cuyos principales elementos son la comunidad humana, el territorio, la idea de Estado indispensable para su realización, todo ello convivido en circunstancias precisas, que forma ese way of life que funde y amalgama en un todo los elementos aislados. $\mathrm{Y}$ el nacionalismo suele ser la hipertrofia desordenada de uno o de alguno de tales elementos: lo social en su infimo sentido racial, la sed de territorios dominados, el pasado glorioso, etc. y, desde luego el crecimiento monstruoso de la idea de Estado, todo lo cual desemboca en esos lamentables y desequilibrados ensayos que han sido la Alemania nazi, la Italia fascista o la España de Franco.

Aplicándonos los mismos principios habremos de convenir en que sano y loable sería el cultivo de lo propiamente mexicano, de lo que provenga $y$ sea coherente $y$ provechoso al desarrollo armónico de nuestro propio complejo social-juridico-cultural, cuyos diversos aspectos y trazos, en grupos particulares o en detalles aislados, tratan de perfilar, investigando desde ángulos diversos, muchos de los colegas que han ocupado o habrán de ocupar este mismo sitio. Mas, por lo mismo que tan digno de encomio es el cultivo de lo mexicano será ignominioso y vituperable alentar sus deformaciones mexicanistas, que van desde la parodia caricaturesca de sus rasgos hasta el crecimiento exagerado de algunos de ellos que, como verdadero cáncer, devoran y debilitan el resto del organismo, lo deforman y lo matan.

Podría creerse que un resabio barroco me induce a extremar los argumentos o que un virus romántico me lleva al fácil camino de profetizar tragedias. Pero es que los síntomas artísticos son particularmente expresivos y ellos revelan la gravedad de una situación. 
Aunque no exclusivas, si pueden calificarse de importantes ciertas corrientes de nuestro arte que lo llevan como en un deseo de alardes mexicanistas. Los ejemplos abundan y hablan por sí mismos del efecto desastroso de tan nefastas corrientes. Las artes populares han padecido en extremo las consecuencias de semejantes aberraciones: la vieja cerámica de Tlaquepaque era cosa de indiscutible mexicanidad con su decoración de grecas, orlas, pájaros y flores en negro sobre blanco o en rojo sobre blanco; hoy la cerámica de ese mismo lugar procurando "mexicanizarse" más, se ha llenado de nopales, burros, inditos, logrando con ellos ser, a los ojos de todos los que conocen y sienten lo mexicano, un pseudo arte para turistas, tanto menos mexicano cuanto más de mexicanismo se llena. Lo mismo podría decirse de los sarapes de Oaxaca y de otras muchas cosas. Algo parecido ocurre con la música que del sentimentalismo tierno y contenido, de la expresión melancólica y suave (caracteres señalados aquí, en su magnifica conferencia, por el investigador folklorista Vicente $T$. Mendoza), tan propios de la canción mexicana en sus mejores ejemplos, hoy se ha desvirtuado y verdaderamente prostituido su indole y sus manifestaciones, en esos inoportunos y exagerados falsetes y en esos prolongados alaridos que el vulgo quintopatiero de la capital (el más vulgar de los vulgos) cree hoy que constituyen el carácter esencial de la canción mexicana, aunque nos conste lo contrario a quienes desde la infancia escuchamos, en las polvosas calles de nuestros pueblos abajeños, corazón de México, las valonas, décimas y canciones suaves, melancólicas y sentimentalmente poéti. cas que, ellas sí, son mramente mexicanas sin esos mexicanismos falsos, forzados y arbitrarios.

Mucho de eso mismo viene ocurriendo, en el último cuarto de siglo, con ciertos géneros ì literatura, sólo para aludir, entre las artes cultas, a la que más me concierne. Si recorremos ese casi medio millar de títulos que Morton cita en su estudio sobre las novelas de la Revolución ${ }^{3}$ (donde corno, de costumbre, ni están todos los que son $\mathrm{y}$, sobre todo, no son todos lo que están), si se leen esos cuentos y novelas causará admiración ver la superabundancia de páginas en las cuales sus autores han querido y creido hacer literatura de la Revolución Mexicana de modo tan violento que tal parece hubiesen sido escritas, por algunos de sus personajes, "a punta de bala", pues así están, edificando perversamente el cuento mexicano en fuerza de construirlo con balazos, caballos, palabras soeces, gritos

3 F. Raxd Morton.-Los Novelistas de la Revolución Mexicana.-Ed. Cultura, México, 1949. 
y sombrerazos. Todo lo cual, naturalmente, no vale ni la quincuagésima parte de aquellas líneas, en sí tan mexicanas, tan pulcramente nacionales sin nacionalismo, como son las de Ramón López Velarde, por ejemplo cuando dice :

Plaza de armas, plaza de musicales nidos,

frente a frente del rudo y enano soportal;

plaza en que se confunden un obstinado aroma

lírico y una cierta prosa municipal...

o bien :

Hasta los fresnos mancos,

los dignatarios de cúpula oronda

han de rodar las quejas de la torre

acribillada en los vientos de fronda...

Precisamente coincidè este lamentable fenómeno en las artes con otras manifestaciones, paralelas en el significado y también en lo deplorable, que vemos en torno nuestro en los campos sociales de la economía y de la política: alardes de nacionalismo tan continuos y extremosos que serian ridículos si no entrañasen graves peligros, risibles si no estuviesen sirviendo de pantallas o de pistas falsas para encubrir realidades bochornosas y para desviar la atención pública apartándola del examen que pondria a la luz actos y direcciones de la política de todo punto censturables. Me refiero a esas pretendidas liberaciones económicas y ese constante alardear de gestos revolucionarios cuando a todos consta que la Revolución se ha detenido hace años, que la industrialización se hace no a favor del pueblo sino de los grandes capitales, gran númoro de ellos extranjeros, que la política interior so pretexto de garantias se apoya fuertemente en las derechas $y$ que la política exterior ha favorecido la continua salida de miles de trabajadores perjudicando aquí la economía nacional y perjudicando allá a los asalariados norteamericanos por la competencia ruinosa de los braceros, todo ello no en favor de ningún pueblo sino particularmente del capitalismo norteamericano. Es decir, 'claramente se ve que mientras más se acentúen los gestos y las proclamas nacionalistas menos se sirve a la verdadera nacionalidad, salvo las necesarias excepciones confirmativas de la regla.

$\mathrm{Y}$ como el arite es una de las más nítidas expresiones de las circunstancias históricas de los pueblos, el fenómeno del nacionalismo encubriendo y provocando actitudes erróneas, es paralelo en lo social y en lo artístico. 
Lo que es repugnante en política, en economia, en organización social, debe serlo también en la cultura y en el arte, pues nadie puede pensar hoy día que estos diversos campos sean islas separadas entre sí cuando, por el contrario, significan. únicamente zonas diversas, pero que en todas ellas $y$ en todas al mismo tiempo, es uno el hombre y el pueblo que las vive, las aprovecha $o$ las sufre. $Y$ si ese extremado nacionalismo de gestos y de palabras es o por lo menos lleva al fascismo, antitético de un sano desenvolvimiento social, por igual motivo debe rechazarse una literatura - un arte cuyos gestos mexicanistas estimulan limitaciones y pasiones perjudiciales en cuanto se prestan a cubrir o desacreditar principios o ideas de mayor hondura y de universalidad, de mayor alcance y nobleza, únicos que favorecen el desarrollo de la solidaridad humana y ayudan a la mejor comprensión de los pueblos todos, to cual es y debe ser uno de los más altos ideales de verdadero humanismo y de verdadera cultura, muy por encima del sentimentalismo localista que sólo sirve para levantar barreras de pueblo a pueblo, -a veces de región a región y casi podríamos decir de villorrio a villorrio.

Porque la nación es comunidad y robustecer la nacionalidad es apretar los vínculos de unión y de común acterdo; precisamente por eso debe evitarse el uso y el estímulo de aquellas formas de expresión que, so pretexto o con la falsa apariencia de subrayar o ilustrar lo mexicano, degeneran en mexicanismos perjudiciales a la auténtica expresión y realización de lo mexicano.

Probablemente, hace años, algunas de las frases antedichas habrian levantado protestas intimas o expresas en los oyentes; espero que eso no pueda suceder $y x^{f}$ en esta segunda mitad del siglo que vivimos. Me refiero a las posibles protestas de quienes se molestarian al descubrir que yo considero que la literatura $y$ el arte tienen, $y$ han tenido siempre, una función social. Confío en que todos estamos convencidos de la vacuidad y falsía del ars gratia artis o sea, en términos más positivos, en que el arte, como producto social, tiene también una función política. $Y$ para nosotros, en estos momentos, uno de los aspectos de tal función política es la expresión y reafirmación de la nacionalidad, de nuestra nacionalidad, de lo cual me parece encontrar la prueba más inmediata en esta búsqueda de los caracteres de lo mexicano a través del arte y de las letras, finalidad que ha movido, entre otras cosas, a la organización de este ciclo de conferencias en que hoy participamos.

Así pues, un uso negativo de nuestras manifestaciones literarias, que debe eyitarse, es lo que atenta a la integridad de lo tiacional como es todo 
aquello que conduce a un nacionalismo de cualquier modo. Pero, en cambio, un tratamiento positivo y fructífero será hacer que nuestras letras ayuden a nuestra nacionalidad conectándola y proyectándoląen un campo más amplio, dirigida a entender y estrechar vínculos más allá de nuestro ámbito social, moviéndola por caminos más universales hacia el ideal de la solidaridad y la comunidad de los hombres todos.

Esa alta función htmanista es hoy de tal modo urgente que yo no vacilaría en afirmar que ella constituye el mejor desideratum que puede asignarse a todos y a cualesquiera de los esfuerzos que se hagan en el terreno de las actividades culturales.

Por lo mismo, en vez de cultivar y alentar los fútiles mexicanismos es preciso encaminar nuestras letras, nuestro arte a mayores alturas y mayor universalidad.

Eso lo considero así, con tanta mayor convicción cuanto que el arte verdadero nunca podrá desprenderse de un fuerte contenido de universajidad. Lo nacional, comprendido con honradez, con hondura y con amplitud no se contrapone a dicha universalidad. Porque es cierto que la expresión artística se realiza tanto más plenamente cuanto mayor es su contenido de carácter propio y el carácter propio es, sin duda, un complejo psicosocial en el cual entran las influencias del medio, del momento histórico, del ambiente todo, junto con la impronta individual del artista, aportación que va desde lo intimo subconsciente, a través de la propia cultura, hasta los conocimientos más elaborados y el dominio de la técnica. En tal sentido de carácter propio se repite, con entera verdad, que si $E l$ Quijote es obra universal lo es por ser, al mismo tiempo, profundamente español, y es claro y obvio que en tal sentido lo nacional no sólo es provechoso y loable sino factor esencial de la obra de arte. Pero teniendo lo nacional como punto de partida, como base $\mathrm{y}$ arranque de la creación artística o literaria debe tenerse también, como blanco al que se apunte, como meta o, más bien, como punto de guía y orientación, que no importa se procure inmediatamente alcanzar, esa universalidad que constituye un ideal supremo.

Sería entender mal el suponer que una obra de arte debe ser, forzosamente, entendida y apreciada igualmente por todos los humanos, desconociendo o tratando de negar las innegables diferencias múltiples $\mathrm{y}$ hondísimas que dividen a la humanidad en el pensamiento, en la acción $y$, más aún en los sentimientos.

La universalidad perfecta es, sin duda, un ideal remoto. Algún dja, asi lo espero, podrá llegarse a la obra de arte que podríamos llamar inte- 
gramente católica, es decir, ecuménica, universal. (Es claro que no me refiero a la iglesia cristiano-romana cuyo nombre de católica queda como huella de su origen bizantino). Al hablar de aquel ideal remoto he querido aludir a un fenómeno, todavía no alcanzado, que corresponde a la clásica definición del quod semper, quod ubique, quod ab omnibus: 10 que es para siempre, para todas partes, para todos.

Con ello no quiero decir que la literatura de México deba tener exclusiva $\mathrm{y}$ únicamente objetivos remotos $\mathrm{y}$ temas universales, lo que digo es que lo universal y perenne debe estar siempre en el punto ideal del horizonte en que confluyen las líneas de la perspectiva, a sabiendas de que no alcanzaremos, ni trataremos de alcanzar, en la obra concreta, ese punto ideal.

Alfonso Reyes, y me complazco en citar a este maestro tan mexicano y $\tan$ universal, ha dicho: "todos los viajeros lo saben: la manera más segura de marearse es fijar los ojos en el costado del barco, allí donde baten las olas. $\mathrm{Y}$ el mejor remedio contra esta atracción del torbellino es levantar siempre la vista y buscar la línea del horizonte. Las lejanías nos curan de las cercanias. La contemplación del rumbo da seguridad a nuestros pasos. Cuando yo hacía mi práctica militar, el sargento instructor solía gritarnos: -Para marchar en línea recta no hay que mirarse los pies ; hay que mirar de frente!". 4

Eso es todo, huir de limitaciones asfixiantes, evitar proximidades que empequeñecen el muñdo, desechar el "color local" cuando no es pincelada caracteristica y amepaza con aturdir de colorines el cuadro necesario de aire, de luz y de vida; hacer, en fin, literatura mexicana pero sin rebuscar los mexicanismos que le den carácter.

Lo mexicano de nuestra literatura ha de surgir no del falsete arbitrario y molesto que cualquier "virtuoso" nacional o extranjero putede lograr, ni del alarido bárbaro, ni de los nopales, huaraches y sombreros de petate en el cuadro o en el botellón; lo mexicano no resultará de los alaridos ni de las palabras soeces, ni de los desfiles de mujeres con rebozo y hombres a caballo entre disparos de treinta-treinta; lo mexicano debe nacer de lo más hondo y profundo de nosotros mismos y si la obra se hace con sincera honestidad ello será de un modo u otro.

4 Alfonso Reyes.-Atenea Politica, en "Tentativas y Orientaciones". Ed. Nuevo Mundo, México, 1944. 
Quiero decir que yo estoy convencido de que, si yo soy mexicano y vivo en México y escribo en México, mi obra será de México, lo mismo si me refiero a una anéctota de mis conterráneos del Bajío que si trato de enfocar, sinceramente, desde yo mismo, los efectos de la revolución francesa o mi admiración por el milagro griego.

Eso es todo lo que creo que en esta ocasión tenía que decir y espero que algo de ello pueda servir a quienes interesa ver, gustar, analizar y tal vez crear la literatura mexicana. 